bureaucratic system and is inclined to imitate public dialogue, widely using manipulative practices. In turn, institutes of civil society most often have not great influence and backing of population, they depend on public and municipal authorities. The article proves that the main obstacles for constructive public communications in constituent entities of the Russian Federation have rather social and sociocultural, but not technological character. They are connected with the fact that in the course of social demarcation the authority usually takes the part of the subjects possessing property and wealth and becomes one of injustice sources in the opinion of contractors, and loses its credibility. At the same time, institutes of civil society have no sufficient potential to expect negative consequences of developed communicative practices and to offer technologies of their modification.

Keywords: region, authority, public communications, institutes of civil society, imitation, falseointeraction, bureaucracy, trust, expert community

ЯКИМЕЦ Владимир Николаевич - доктор социологических наук, кандидат технических наук, профессор Российской академии народного хозяйства и государственной службы при Президенте РФ, главный научный сотрудник Института проблем передачи информации им. А.А. Харкевича РАН (127994, Россия, г. Москва, Б. Каретный пер. 19, cтр. 1; iakimets@таil.ru)

НИКОВСКАЯ Лариса Игоревна - доктор социологических наук, доцент; главный научный сотрудник Института социологии ФНИСЦ РАН (117218, Россия, г. Москва, ул. Кржсикановского, 24/35, cmp. 5; nikovsky@inbox.ru)

\title{
МЕХАНИЗМЫ И ПРИНЦИПЫ МЕЖСЕКТОРНОГО СОЦИАЛЬНОГО ПАРТНЕРСТВА КАК ОСНОВА РАЗВИТИЯ ОБЩЕСТВЕННО-ГОСУДАРСТВЕННОГО УПРАВЛЕНИЯ
}

\begin{abstract}
Аннотация. За последние 5-7 лет наблюдается зримое снижение эффективности и качества государственного управления. В представленной статье обосновывается необходимость смены парадигмы системы государственного управления - перехода от устаревшей модели к общественно-государственному управлению (ОГУ). В статье авторы дают определение основных понятий, таких как ОГУ, субъекты и акторы ОГУ, публично-правовые институты ОГУ, механизмы ОГУ, а также приводят примеры уже работающих в РФ институтов и механизмов ОГУ.

Ключевые слова: общественно-государственное управление, субъекты и акторы, публично-правовые институты и механизмы общественно-государственного управления, межсекторное социальное партнерство, общественное участие.
\end{abstract}

\section{Актуальность задач повышения эффективности системы госуправления в России}

Изменяющееся общество в политическом контексте начала XXI в. формирует запрос на расширение доступа граждан и организаций гражданского общества к процессу принятия решений, увеличение прозрачности власти и ее ответственности за свою деятельность перед обществом [Dalton, Scarrow 2003]. Это стимулировало разработку новой концепции государственного управления для XXI в., предусматривающей обеспечение широкого доступа граждан и бизнеса к правительственной информации, прежде всего в сфере образования, здравоохранения и социального обеспечения, занятости, налогообложения, лицензирования и ведения бизнеса, государственных закупок и госзаказов, международных торговых операций. Концепция также предусматривала предоставление гражданам новых каналов коммуникации, позволяющих им 
участвовать в выработке «правил игры», определяющих отношения между государством и гражданами, и осуществлять постоянный контроль за тем, как эти правила соблюдаются [Мэннинг, Парисон 2003]. Таким образом, четко обозначившийся мейнстрим общественной мысли в отношении критериев оценки качества госуправления обозначил возрастание значимости «горизонталей» в общественном развитии, ограниченность потенциала иерархически организованного политико-административного управления и противопоставил ему концепцию управления governance, в которой интенсивность отношений государства и общества рассматривается в качестве основы повышения эффективности публичного управления, с одной стороны, и его демократичности - с другой.

В своем послании ФС РФ 1 марта 2018 г. президент РФ сделал политический акцент на том, что сила государства определяется не столько природными ресурсами и производственными мощностями, сколько качеством жизни, уровнем благосостояния граждан, возможностями для творческой самореализации и развития каждого человека. «Чтобы идти вперед, динамично развиваться, мы должны расширить пространство свободы, причем во всех сферах, укреплять институты демократии, местного самоуправления, структуры гражданского общества, судов, быть страной, открытой миру, новым идеям и инициативам» ${ }^{1}$. И это возможно только при новом качестве государственного и муниципального управления. В то же время в последние годы мы наблюдаем снижение эффективности и качества деятельности системы госуправления, что беспокоит граждан, политиков и научное сообщество и требует предпринять какие-то осмысленные шаги по мониторингу ситуации и поиску путей и способов выхода из сложившегося негативного тренда. Так, согласно материалам Счетной палаты РФ², выявлено неэффективное использование федеральных и иных ресурсов на общую сумму 965,8 млрд руб. При этом общая сумма выявленных СП нарушений и недостатков в 2016 г. выросла на $87 \%$ по сравнению с 2015 г. Выступая на Гайдаровском форуме, руководитель Счетной палаты РФ Т. Голикова констатировала наличие системных проблем в системе госуправления на основе обобщения результатов 4-летнего изучения «взаимосвязи качества государственного управления и эффективности расходов, которые администрируются этой системой госуправления». В своих рекомендациях руководитель СП предложила «вернуться в начало пути и еще раз определиться с основными принципами разграничения уровней государственного управления. В том числе и с целесообразностью сохранения трехуровневой модели» ${ }^{3}$.

Имеются определенные проблемы и в деятельности органов региональной власти. В конце 2017 г. Президент РФ был подписал указ «Об оценке эффективности деятельности органов исполнительной власти субъектов Российской Федерации» ${ }^{4}$, в котором поставлена задача разработки методики оценки их деятельности, а также определена процедура предоставления докладов о достижении значений показателей этой оценки.

1 Послание Президента РФ Федеральному Собранию РФ 01.03.2018. Доступ: http://kremlin.ru/ events/president/news/56957/work (проверено 16.03.2018).

2 Отчет о работе Счетной палаты РФ за 2016 год. Доступ: http://audit.gov.ru/activities/annual_ report/\#896 (проверено 16.03.2018).

3 Выступление Т. Голиковой на Гайдаровском форуме по теме «Эффективность бюджетных расходов как зеркало госуправления». 17 января 2018 г. Доступ: http://audit.gov.ru/structure/golikova-tatyanaalekseevna/speeches/32283/ (проверено 16.03.2018).

4 Указ Президента РФ «Об оценке эффективности деятельности органов исполнительной власти субъектов Российской Федерации» № 548 от 14.11.2017. Доступ: http://www.consultant.ru/document/ cons_doc_LAW_182660 (проверено 14.06.2017). 


\section{Общественно-государственное управление как новый этап развития}

\section{государственного управления}

На наш взгляд, приступая к поиску путей совершенствования деятельности системы госуправления, необходимо разобраться и с рядом теоретических положений. С учетом фактора растущего общественного и гражданского участия в развитых и развивающихся странах все большую популярность приобретают концепции эффективного государственного управления. Концепции совместного управления (governance) и хорошего управления (good governance) были впервые изложены в программных документах $\mathrm{OOH}^{1}$. Весомая роль в оценке качества госуправления отводится общественному контролю за деятельностью органов государственной власти, вовлеченности граждан в процесс принятия и исполнения решений. Институциональная среда должна предоставлять возможность аккумулировать мнения многочисленных политических и общественных акторов, способствовать обмену мнений, поиску консенсуса при принятии политических, экономических, социальных и иных решений, имеющих поддержку широких общественных кругов.

Совет Европы выделил 12 основных принципов, лежащих в основе «хорошего управления» (good governance): честные и справедливые выборы, представительство и участие граждан в выработке и принятии управленческих решений, оперативность и отзывчивость, открытость и прозрачность, верховенство права во всех сферах общественно-политической жизни, этичное поведение всех участников управления, инновационность в работе и открытость к переменам, устойчивость и ориентация на долгосрочную перспективу, рациональное управление финансами, ответственность чиновников за принимаемые решения и др. ${ }^{2}$

Названные принципы организации в большей степени применимы к уровню местной власти, т.к. именно на данном уровне население имеет непосредственные рычаги контроля за органами власти и участия в процессах управления. Но и для уровня федеральной власти эти принципы не теряют своей актуальности, являясь основными ориентирами в их деятельности.

Существенным фактором в развитии института общественного контроля в развитых демократиях стало развитие информационных технологий, которые создали возможность доступа к многочисленным информационным ресурсам органов исполнительной власти. Интернет сблизил чиновников и представителей гражданского общества. Интернет-технологии не только позитивно повлияли на улучшение качества общественного контроля, но и способствовали повышению гражданского участия в управлении (совместное управление). С другой стороны, весьма часто политика открытости и прозрачности носит лишь фасадный характер -информация, предоставляемая в открытом доступе гражданам, не является исчерпывающей и понятной, истинные процессы скрываются от глаз граждан, усложняются коррупционные схемы и связанные с ними издержки [Явчуновская 2015: 343].

Развитие интернет-технологий в определенной мере, но в то же время весьма специфически сгладило традиционные виды общественного неравенства имущественного, географического, возрастного, гендерного.

Анализ особенностей работы институтов в рамках публичной политики подводит нас к очень важному принципу модернизации системы - формированию эффективного государства, работающего на принципах good governance,

\footnotetext{
${ }^{1}$ Human development report 1997. URL: http://hdr.undp.org/sites/ default/files/reports/258/hdr_1997_ en_complete_nostats.pdf (accessed 25.04.2016).

$\overline{2}$ The 12 principles for good governance at local level, with tools for implementation. URL: http://www.coe. int/t/dgap/localdemocracy/strategy_innovation/12principles_EN.asp (accessed 25.04.2016).
} 
предполагающего справедливый общественный строй, обеспечивающий личную свободу, защищенность интересов и право на стремление к счастью. По мнению О.В. Гаман-Голутвиной, «становление институтов российского государства показывает, что в настоящее время достигнутые результаты демонстрируют слабую чувствительность отечественной государственности к распространяющейся в передовой части мира модели «активизирующегося государства» [Гаман-Голутвина 2010].

Заметим, что федеральная исполнительная власть начала движение в сторону сформировавшегося общественного запроса: с января 2014 г. утверждена Концепция открытости федеральных органов исполнительной власти (ФОИВ). Концепция, ее методические рекомендации составляют так называемый стандарт открытости ФОИВ. Он направлен на повышение эффективности и результативности мер по совершенствованию системы госуправления, определенных указами Президента России от 7 мая 2012 г. и Основными направлениями деятельности Правительства России на период до 2018 года. Меры включают: продолжение внедрения механизмов «электронного правительства»; организацию широкого многоканального доступа к общедоступным ресурсам; выстраивание системы обратной связи с гражданским обществом; внедрение системы внутренней и внешней оценки ФОИВ, влияющей на последующие кадровые, финансовые и иные решения; упрощение процесса государственного нормотворчества; отражение общественно значимых результатов, на достижение которых направлена работа министерств и ведомств; доведение информации о работе ФОИВ до граждан в понятных форматах. По сути, указом № 601 «Об основных направлениях совершенствования государственного управления» от 7 мая 2012 г. президент РФ В.В. Путин наметил «дорожную карту» развития общественно-государственного управления [Якимец 2015a: 214], определив содержание нововведений и сроки их реализации. В нем, в частности, прописано задание на разработку концепции российской общественной инициативы, предусматривающей создание условий для публичного представления предложений граждан в сети Интернет с последующей проработкой тех из них, которые получат поддержку не менее 100 тыс. граждан в течение одного года. Однако не у всех инициатив, набравших более 100 тыс. голосов, складывается благоприятная судьба. Так, рабочая группа открытого правительства отклонила общественную инициативу о применении в России ст. 20 Конвенции ООН против коррупции. Этой инициативой предусматривалось введение уголовной ответственности для чиновников, которые не смогли бы объяснить свои расходы. Иными словами, рабочая группа отклонила введение в Уголовный кодекс РФ статьи «Незаконное обогащение».

Несмотря на широкое распространение социальных сетей в обществе, государство не закрепило их официальный юридический статус как полноправных площадок для формулирования и транслирования гражданских инициатив во властные структуры.

В 2014 г. с целью усиления роли публичной политики в системе управления было предложено использовать более отвечающее требованиям времени понятие «общественно-государственное управление» (далее - ОГУ) [Якимец 2015а: 214] взамен термина «государственное управление». Системно концепция ОГУ - «это подход, модернизирующий политику, процедуры, структуры и системы управления и ведения государственных дел (всех видов деятельности) на всех уровнях исполнительной власти за счет развития публично-правовых институтов и механизмов, введения действенных процедур учета общественных интересов на основе изучения лучших практик, организации и расширения общественного участия и согласования межгрупповых отношений, обеспечивающих 
синергетический эффект, вследствие инкорпорирования принципов, моделей и механизмов публичной политики и межсекторного социального партнерства в процессы подготовки, принятия и реализации управленческих решений» [Якимец 2015б: 240]. Исходя из этого, насущной задачей становится пересмотр концепции и процедур государственного управления на всех уровнях, внесение изменений в систему обучения по этой дисциплине в вузах страны.

Перенос в 1990-е гг. в российскую действительность термина public administration и связанных с ним теоретических постулатов, принципов и механизмов происходил без достаточного осмысления и привел к тому, что мы получили понятие «государственное управление», из которого исчезло важнейшее прилагательное - «общественное» (public). Отметим, что дословный перевод public administration как «публичная администрация» или «публичное управление» был не совсем приемлем для России, и поэтому остановились на термине «государственное управление». Тем самым была выстроена иерархия - «органы государственной власти и управления», - где госвласть выступала в качестве субъекта управления, а «общество» во всех его проявлениях - как объект управления, подчиненный указанному субъекту. То есть, в условиях перехода к рыночной экономике была, по сути дела, реставрирована советская модель государственного управления с постоянно усиливающейся доминантой бюрократического аппарата и чиновничества.

Предпринимались попытки скорректировать термин. Нам импонирует такое рассуждение: «Все больше оснований рассматривать "public administration" (далее PA) и "public management" как «общественное (публичное) управление», ключевыми участниками которого являются не только сами чиновники или государственные служащие, но и... другие акторы, являющиеся частью гражданского общества» [Купряшин, Соловьев 2012: 12]. Соглашаясь с авторами, мы, тем не менее, считаем, что рассматривать РА как «общественное (публичное) управление» не совсем удачно для России, в т.ч. и потому, что основными субъектами управления остаются органы государственной власти и госслужащие. Поэтому в названии целесообразно сохранить слово «государственное». Было предложено перейти к концепции общественно-государственного управления (ОГУ) [Якимец 2015а: 214], при этом в английском варианте использовать словосочетание public-state governance [Yakimets 2017: 257], заменяя последним словом administration. Уместность слова governance здесь объясняется не столько его популярностью, сколько его адекватностью современным тенденциям развития [Fukuyama 2013]. Из определения понятия governance, приведенного на сайте Всемирного банка ${ }^{1}$, следует, что это «совокупность традиций и институтов, на основе которых функционирует власть в стране, включающая процедуру формирования правительств, их контроля и замены; потенциал и способности правительства по эффективному определению и реализации четкой политической программы; уважение граждан и государства к институтам, с помощью которых осуществляется управление экономическими и социальными взаимодействиями между ними». Важно, что при большем акценте на концепт governance «государство становится менее бюрократичным, сокращается иерархическая зависимость от центральной власти при исполнении полномочий. Ответственность за проводимую публичную деятельность все больше связывается с эффективностью и результативностью, а не только с достижением конкретной цели политики в рамках закона» [Frederickson, Smith 2003]. Зафиксируем, что при этом возникает необходимость четко различать а) субъектов и акторов ОГУ и б) публично-правовые институты и механизмы ОГУ.

${ }^{1}$ What is Governance? URL: http://info.worldbank.org/governance/wgi/\#home (accessed 05.06.2017). 
Для того чтобы взаимодействие в смысле ОГУ не только стало возможным, но и имело партнерский характер, стали формироваться и применяться на практике соответствующие правила и процедуры, которые мы условно разбили на две группы: публично-правовые институты ОГУ и механизмы ОГУ [Якимец 2017: 123].

Публично-правовые институты (далее - ППИ) - это конструкции, которые функционируют в соответствии с нормами, прописанными в законах РФ. В качестве примера назовем оценку регулирующего воздействия (закреплена федеральным законом от 02.07.2013 N 176-Ф3). Еще один пример ППИ - это бурно развивающаяся совокупность механизмов государственно-частного партнерства на основе норм федерального закона от 13.07.2015 N 224-Ф31.

В отличие от ППИ, механизмы ОГУ - это, как правило, созданные совместно представителями власти и различными негосударственными акторами системы и процедуры взаимодействия, легитимность которых закреплена в нормативных правовых актах (НПА) разного уровня. Например, здесь можно назвать конкурсные механизмы предоставления субсидий социально ориентированным НКО; платформы краудсорсинга для сбора предложений по решению насущных проблем, улучшению качества управления и работы учреждений и организаций или механизм инициативного бюджетирования.

Известно, что развитие механизмов общественного участия, институтов публичной политики, механизмов межсекторного социального партнерства содействует рационализации и эффективности взаимодействия власти и общества и позитивно сказывается на совершенствовании и результатах государственного управления.

Общественно-государственное управление призвано аккумулировать интересы и потребности общества, его основных социальных групп с целью выработки оптимальных средств и методов их удовлетворения. Именно существенные сдвиги в среде гражданского общества, когда наметилась тенденция перераспределения центра тяжести гражданской активности от политических партий в сторону неполитических общественных объединений, заставили постепенно реформироваться государство в направлении расширения рамок его открытости обществу, его запросам. И роль «драйвера» такой трансформации госуправления взяло на себя межсекторное партнерство - как технология, соединяющая поиск баланса интересов между бизнесом, некоммерческим сообществом и государством на основе выявления «зон согласия», поиска компромиссов в условиях плюрализма и несовпадения частных, групповых и административных интересов.

\section{Механизмы межсекторного социального партнерства в системе ОГУ}

Межсекторное партнерство во всем многообразии своего проявления, дополняя электоральную систему представительства интересов «демократией со-участия», пытается встроить максимальное количество социальных интересов в процессы выработки и реализации государственной политики и формирования модели «со-управления» в условиях современного общества.

Сущность содержательного концепта «межсекторное социальное партнерство» (далее - МСП) состоит в конструктивном взаимодействии организаций из двух или трех секторов (государство, бизнес, некоммерческий сектор) при решении социальных проблем, выгодном населению территории и каждой из

1 Федеральный закон «О государственно-частном партнерстве, муниципально-частном партнерстве в Российской Федерации и внесении изменений в отдельные законодательные акты Российской Федерации» от 13.07.2015 N 224-Ф3. Доступ: http://www.consultant.ru/document/cons_doc_LAW_182660 (проверено 14.06.2017). 
сторон, обеспечивающем синергетический эффект от сложения разных ресурсов [Якимец 2002: 6]. Представители каждого сектора имеют разные возможности и ресурсы для участия в решении проблем социальной сферы, у них разные представления о самой природе социальных проблем. Но, несмотря на все различия, сотрудничество секторов необходимо: ни государство, ни бизнес, ни граждане не могут в одиночку преодолеть груз накопившихся социальных проблем и разрешить конфликты.

К концу нулевых годов на федеральном уровне усилиями Министерства экономического развития и представителей ряда крупных некоммерческих организаций было выявлено два принципиальных системообразующих момента: во-первых, государственная поддержка общественных инициатив гораздо эффективнее, чем любая попытка реформирования «сверху»; во-вторых, без понимания и заинтересованного участия общественности любая инициатива органов власти изначально обречена на провал [Роль институтов... 2010: 146]. Формирование консолидированных и созидательных практик через МСП важнейший технологический и ценностный ресурс. Социальная консолидация является фундаментальной основой развития российского общества, необходимым условием инновационного прорыва в развитии страны, выполнения стратегических планов, которые были декларированы руководством страны.

Согласно исследованиям, проведенным нами, МСП укоренилось в нормативно-правовом пространстве всех субъектов РФ. В 2009-2010 гг. в каждом из субъектов РФ были изучены нормативные правовые документы, в которых содержалось описание применяемых механизмов МСП [Якимец, Исаева 2011: 102]. Всего в качестве устойчиво работающих были выделены пять типов механизмов МСП: конкурсные, социально-технологические, организационноструктурные, процедурные (или переговорные), комплексные (или комбинированные).

При развитии системы партнерства расширяются возможности для удовлетворения разнообразных социально-экономических, социальных, политических, культурных, этноконфессиональных и иных интересов граждан. Складывается атмосфера доверия и сотрудничества, «со-участия» между ними и системой государственной власти.

В целом, на сегодняшний день насчитываются более тысячи разнообразных механизмов МСП, созданных представителями гражданской и деловой инициативы на региональном и местном уровнях [Якимец 2010: 15]. И все они являются в той или иной степени социальными новациями.

Способы и формы взаимодействия НКО и власти, «отлитые» в определенную совокупность социальных действий, весьма разнообразны. Прежде всего, это прямое информирование о проблемах и противоречиях, которыми озабочено общество, о собственных действиях по их разрешению, в т.ч. и о тех проблемах, которые вызывают не только социальное напряжение, но и социальное противостояние, т.е. речь идет уже и о сложившихся конфликтных ситуациях. Особое место в инициируемых НКО формах взаимодействия с властью занимают налаживание диалога в форме переговоров, консультаций, круглых столов и прочих информационно-согласительных процедур. В результате, пока еще не повсеместно, но появляются устойчивые структуры взаимодействия в виде совместных рабочих групп, общественных и экспертных советов, общественных палат и пр., что свидетельствует о начавшемся процессе институционализации взаимоотношений структур гражданского общества и власти. И этот процесс, опирающийся на сформировавшиеся социальные технологии, приобретает системный характер. 


\section{«Административная гильотина» - пример эффективного трехсекторного социального партнерства в системе ОГУ}

В 2013-2014 г. авторы совместно с коллегами из Костромы, Казани и Ярославля реализовали проект по выявлению, описанию и анализу успешных практик отстаивания гражданами и некоммерческими организациями общественных интересов на региональном и муниципальном уровнях. Материалы исследований были опубликованы в двух сборниках [Практики формирования...2014; Возможности и барьеры...2014].

Среди детально изученных 12 кейсов выделялся проект, получивший название «Административная гильотина», реализованный командой, включавшей представителей всех трех секторов - государства, бизнеса, некоммерческих организаций - из Пермского края. Представим в данном разделе краткое описание данной практики [Якимец 2014: 8].

В 2011 г. проект «Административная гильотина» был инициирован Пермской торгово-промышленной палатой (ТПП) при поддержке правительства края. Комиссия по административному дерегулированию совместно с органами власти региона и г. Перми разрабатывала меры по уменьшению сроков оказания государственных и муниципальных услуг предпринимателям. Дело в том, что в крае, как и во многих иных субъектах РФ, одним из главных факторов, сдерживающих развитие бизнеса и негативно сказывающихся на бизнес-климате, являются сроки выдачи разрешительной документации. Время, затрачиваемое на оказание государственных и муниципальных услуг, неблагоприятно сказывается на формировании инвестиционной среды в регионах, в частности за счет увеличения сроков реализации проектов. В большинстве субъектов РФ такие вопросы административной реформы лежат в сфере деятельности органов власти и решаются (если решаются вообще) именно ими. В Пермском крае изначально инициатива реализации проекта исходила от бизнеса в лице краевой ТПП. Проект был поддержан губернатором Пермского края, который дал поручение исполнительным органам государственной власти принять участие в осуществлении инициативы. В реализации проекта участвовал общественный фонд «Центр гражданского анализа и независимых исследований «Грани» (далее - центр «Грани»). Иными словами, было налицо партнерство организаций из всех трех секторов. Сформированная рабочая группа, куда вошли представители органов региональной власти и местного самоуправления, ТПП, предприниматели, центр «Грани», такие общественные организации, как «Опора России», «Деловая Россия», и эксперты, выяснила, что основной проблемой для бизнеса при прохождении административных разрешительно-согласовательных процедур являются значительные временные затраты, а также лицензирование и сертификация, проверки налоговых и иных контрольно-надзорных органов (технических, санитарных, МЧС). Были выявлены также основные типы административных барьеров (правил, уложений и пр.), на преодолении которых предприниматели несли существенные транзакционные издержки. По итогам работы экспертной группы было принято решение о создании специального межведомственного органа - региональной Комиссии по государственному дерегулированию. В состав Комиссии вошли представители от всех трех секторов - бизнеса, власти и некоммерческих объединений. Предлагая меры по снижению административных барьеров, участники созданной структуры зафиксировали позицию, которая была принята всеми заинтересованными сторонами: принуждение ведомств и муниципалитетов к уменьшению нормативного срока оказания государственной (муниципальной) услуги. Характеризуя достигнутые результаты совместного проекта, президент Пермской ТПП М. Биматов выделил следующие его позитивные итоги. 
- Ведомства создали 44 программы по сокращению сроков выдачи разрешений, из них 21 программа мероприятий государственных органов исполнительной власти Пермского края и 23 - органов местного самоуправления.

- В результате реализации этих программ общее время, нужное для выдачи разрешений, сократилось на 512 дней, что возвратило в хозяйственный оборот 2 млрд руб. бюджетных средств.

- Установлено, что краевые ведомства числили за собой исполнение 137 функций, но на самом деле их оказалось 273.

- Выявлено, что 40 функций, исполняемых ведомствами, вообще не имеют ограниченных чем-либо сроков согласования; 6 функций оказались бессодержательными, а в 14 функциях отсутствовал центр ответственности, и потому процесс выдачи разрешений мог длиться неограниченно долго.

- Срок оказания 10\% государственных услуг сократился на 30-50\% .

- Промежуточным итогом работы комиссии стало сокращение общего срока выдачи разрешений в Пермском крае до 2561 дня (для сравнения, в России общий срок выдачи разрешений составляет 3 тыс. дней).

- Реализация проекта позволяет сэкономить предпринимателям Пермского края около 10 млн руб. и возвратить почти 1,2 млрд руб. в оборот компаний.

Таким образом, результаты работы проекта ярко демонстрируют эффективность такой модели ОГУ.

Итак, налицо мощный потенциал межсекторного взаимодействия для повышения эффективности ОГУ на региональном уровне. Результаты внедрения механизмов «Административной гильотины» продемонстрировали, что можно не только навести элементарный порядок в системе управления, но и получить значимый экономический и социальный эффект.

Таким образом, технологии, механизмы межсекторного партнерства - при сформированных правовых подходах - становятся важным ресурсом эффективного управления государственными делами. Они позволяют выявлять и технологично продвигать назревшие социальные запросы и интересы активных социальных групп и общественной гражданской инициативы, направленные на углубление демократических процессов преобразования общества. Одной из таких инновационных технологий стала успешная практика «Административной гильотины», показавшая позитивный интегральный эффект от крепнущего межсекторного взаимодействия и партнерства власти, бизнеса и некоммерческого сообщества. Межсекторное партнерство, встроенное в систему ОГУ, может конструктивно дополнять и видоизменять административную вертикаль политико-государственного управления за счет включения растущей гражданской активности низовых звеньев социума. Сформулированные президентом РФ «прорывные задачи» посткризисного развития страны требуют именно такого полноценного и действенного социального партнерства и встраивания его в систему публичного государственного управления.

\section{Список литературы}

Возможности и барьеры улучшения региональных механизмов формирования и отстаивания общественных интересов (под ред. В.Н. Якимца, Л.И. Никовской, А.В. Соколова). 2014. Ярославль: ИП Дурынин. 148 с.

Гаман-Голутвина О.В. 2010. Авторитаризм развития или авторитаризм без развития: судьбы модернизации на постсоветском пространстве. - Вестник МГИМО. № 4. С. 77-85.

Купряшин Г.Л., Соловьев А.И. 2012. Теория и механизмы современного государственного управления. М.: Изд-во МГУ. 642 с. 
Мэннинг Н., Парисон Н. 2003. Реформа государственного управления: международный опыт. М.: Весь Мир. 496 с.

Практики формирования и отстаивания общественных интересов: опыт регионов России (под ред. В.Н. Якимца, Л.И. Никовской, А.В. Соколова). 2014. Ярославль: ИП Дурынин. 127 с.

Роль институтов гражданского общества в стратегии инновационного развития и повышения качества социальной среды. 2010. М.: ИСПИ РАН. 224 с.

Явчуновская Р.А. 2015. Общественный контроль в странах ЕС и США. Формирование гражданского общества в России: стратегии и управление (под ред. Л.Е. Ильичевой). М.: Аналитик. С. 343-345.

Якимец В.Н. 2002. Межсекторное социальное партнерство (государство - бизнес - некоммерческие организации). М.: ГУУ. 80 с.

Якимец В.Н. 2010. Проблемы оценки и мониторинга гражданского общества в регионах России. - Оценка состояния и развития гражданского общества России: Проблемы, инструменты и региональная специфика (под ред. В.Н. Якимца). Труды ИСА РАН. Т. 57. М.: Красанд.

Якимец В.Н., Исаева Е.А. 2011. Рейтинг субъектов РФ по продвижению механизмов межсекторного социального партнерства и описание нормативно-правовой базы, регулирующей деятельность гражданского общества в Ярославской области. - Индексы оценки развития гражданского общества в регионах России: сборник научных трудов. М.: ИСА РАН. С. 102-110.

Якимец В.Н. 2014. Административная гильотина (П-кейс). - Практики формирования и отстаивания общественных интересов: опыт регионов России (под ред. В.Н. Якимца, Л.И. Никовской, А.В. Соколова). Ярославль: ИП Дурынин. С. 8-14.

Якимец В.Н. 2015a. Общественно-государственное управление. Государственное управление: Российская Федерация в современном мире. Материалы XII Международной конференции факультета государственного управления МГУ им. М.В. Ломоносова. 29-31 мая 2014 г. М.: Инфра-М. С. 214219. Доступ: http://znanium.com/catalog.php?bookinfo=514674. (проверено 16.03.2017).

Якимец В.Н. 2015б. Состояние и направления развития публичной политики в России: механизмы, примеры, проблемы и перспективы. - Управление публичной политикой: коллективная монография (под ред. Л.В. Сморгунова). М.: Аспект Пресс. С. 240-251.

Якимец В.Н. 2017. Новые форматы общественно-государственного управления в России. - Государство и граждане в электронной среде: сборник научных статей. Вып. 1. СПб: Университет ИТМО. С. 123-135.

Dalton R.J., Scarrow S.E. 2003. Democracy Transformed? Expanding Political Opportunities in Advanced Industrial Democracies. Paper 03-04, Center for the Study of Democracy, University of California, Irvine. URL: http://repositories.cdlib.org/ csd/03-04 (accessed 12.03.2017).

Frederickson H.G., Smith K.B. 2003. The Public Administration Theory Primer. Boulder, Colorado: Westview Press. 450 p.

Fukuyama F. 2013. What Is Governance? CGD Working Paper 314. Washington, DC: Center for Global Development. URL: http://www.cgdev.org/content/publications/ detail/ 1426906 (accessed 12.06.2017).

Yakimets V.N. 2017. New Formats of Public-State Governance in Russia. IMS 2017. June 21-24, 2017, Saint Petersburg, Russian Federation. ACM International Conference Proceeding Series. P. 257-264. URL: https://doi.org/10.1145/3143699.3143705 (accessed 16.03.2018). 
YAKIMETS Vladimir Nikolaevich, Dr.Sci. (Soc.), Cand.Sci. (Tech.Sci.); Professor of Russian Presidential Academy of National Economy and Public Administration, Chief Researcher of Institute for Information Transmission Problems, RAS (19 Bol'shoj Karetny Lane, Moscow, 127994, Russia; iakimets@mail.ru)

NIKOVSKAYA Larisa Igorevna, Dr.Sci. (Soc.), Principal Researcher of the Sociological Institute - branch of the Federal Center of Theoretical and Applied Sociology, Russian Academy of Sciences (bld. 5, 24/35 Krzhizhanovskogo St, Moscow, Russia, 117218; nikovsky@inbox.ru)

\title{
MECHANISMS AND PRINCIPLES OF INTERSECTORAL SOCIAL PARTNERSHIP AS A BASIS FOR DEVELOPING THE PUBLIC-STATE GOVERNANCE
}

Abstract. Over the past 5-7 years, there has been a marked a decline in the efficiency and quality of public administration. The article substantiates the necessity of changing the paradigm of public administration system - the transition from a legacy model to a public-state governance (PSG). The authors give definitions of the basic concepts, such as PSG, PSG officials and actors, public law institutions of PSG, PSG mechanisms. The article also highlights examples of the PSG institutions and mechanisms already operating in Russia. It is shown that as a driver of this transformation of public administration favoured the theory and mechanisms of intersectoral social partnership, which connects the search of balance of interests between business, non-profit community and government on the base of identification of areas of agreement and compromise in conditions of pluralism and divergent private group and administrative interests. The paper gives description of the concept of intersectoral social partnerships and a typology of mechanisms of such partnership. The example of one implemented version of the three-sector social partnership is considered in detail, showing that the authorities, business and non-profit organizations, acting together, can solve long-standing problems of management, achieving both economic effects and socially significant results.

Keywords: public-state governance, officials and actors, PSG public-law institutes and mechanisms, intersectoral social partnership, public participation

АЛЕКСЕЕВ Алексей Владимирович - соискатель кафедры политологии и государственной политики Среднерусского института управления - филиала Российской академии народного хозяйства и государственной службы при Президенте РФ (302028, Россия, г. Орел, б-р Победы, 5A; alalv1978@ gmail.com)

\section{ГИБРИДНАЯ МОДЕЛЬ ГОСУДАРСТВЕННО- ЦЕРКОВНЫХ ОТНОШЕНИЙ В СОВРЕМЕННОЙ РОССИИ}

\begin{abstract}
Аннотация. В статье рассматривается феномен гибридности государственно-церковных отношений в современной России. Форма политического режима влияет на взаимоотношения с конфессиями. Существующая модель государственно-церковных отношений имитирует кооперационную модель, по сути, являясь авторитарной.
\end{abstract}

Ключевые слова: государство, церковь, модель государственно-церковных отношений, гибридность, политизация

\footnotetext{
$\mathrm{B}_{\mathrm{c}}^{\mathrm{c}}$ современной России православная церковь занимает особое положение: об этом рассуждают политики ${ }^{1}$, религиозные деятели, об этом косвенно

1 Выступление Президента России В.В. Путина во время праздничного концерта в Храме Христа Спасителя по случаю 70-летия Святейшего Патриарха Кирилла. - Официальный сайт Московского Патриархата. 22.11.2016. Доступ: http://www.patriarchia.ru/db/text/4694573.html (проверено 25.03.2018).
} 